Check for updates

Cite this: RSC Adv., 2017, 7, 31009

Received 5th April 2017

Accepted 8th June 2017

DOI: $10.1039 / c 7 r a 03877 a$

rsc.li/rsc-advances

\section{Investigation of [Emim][OAc] as a mild pretreatment solvent for enhancing the sulfonation efficiency of alkali lignin}

\begin{abstract}
Zhili Zhang, ${ }^{a}$ Rendang Yang, (D) *a Wenhua Gao and Xianping Yao ${ }^{\mathrm{b}}$
The chemical recalcitrance and complex structure of lignin macromolecules make them difficult to meet the needs of real production processes and limit their high-value utilization. Hence, an efficient and economic method to break the recalcitrance under mild conditions is meaningful and purposeful. In this study, 1-ethyl-3-methylimidazolium acetate ([Emim] [OAc]) was employed to pretreat alkali lignin (AL). Then the dissolving properties and behaviors of $A L$ in [Emim] [OAc] were investigated. In addition, the apparent standard Gibbs energy change $\left(\Delta G^{\circ}\right)$, the standard apparent entropy change $\left(\Delta S^{\circ}\right)$, and the apparent standard enthalpy energy change $\left(\Delta H^{\circ}\right)$ of lignin in [Emim] [OAc] were estimated by using the experimental solubility data. The regenerated lignin $(\mathrm{RL})$ from [Emim] [OAc] was also analyzed by Fourier transform infrared spectroscopy (FT-IR), Scanning Electron Microscopy (SEM), GPC, TG analysis and ${ }^{31} \mathrm{P}-$ NMR spectroscopy. Importantly, the water solubility and sulfonated degree of RL were increased by $14.6 \%$ and $33.6 \%$, respectively. Such results imply that [Emim] [OAc] pretreatment could improve the sulfonation efficiency and make the development of lignin-based products a real possibility.
\end{abstract}

\section{Introduction}

Lignin, the second most abundant renewable resource after cellulose, has attracted increasing attention in recent decades due to its being biodegradable, renewable, and environmentally friendly. ${ }^{1,2}$ Worldwide production of lignin from chemical pulping solutions is approximately 26 million tons/year. ${ }^{3}$ The native lignin molecule contains many functional groups such as carbonyl group, methoxy group, phenolic hydroxy group, alcoholic hydroxy group, ether bond and conjugated double bond, ${ }^{4}$ which suggests it has the potential to be used to prepare various kinds of functional materials. Unfortunately, due to its complicated primary structure, poor solubility, low reactivity and high resistance, only a relatively small portion of lignin isolated from lignocellulosic biomass is already used commercially as oil well drilling additives, concrete additives, agricultural chemicals and industrial binders. ${ }^{5}$ Recently, in order to maximize its full value, great academic interest has been devoted to developing lignin-based products to explore the high value-added utilization of lignin resources. ${ }^{6,7}$ The most common and simplest way to improve the properties and value of lignin is chemical modification (such as hydrolysis, pyrolysis, graft copolymerization, amination, alkylation, sulfonation,

${ }^{a}$ State Key Laboratory of Pulp \& Paper Engineering, South China University of Technology, Guangzhou 510640, PR China. E-mail: rendangyang@163.com; Fax: +86020 87110084; Tel: +86020 87110084

${ }^{b}$ Hangzhou Research Institute of Chemical Technology Co. Ltd., Hangzhou 310000, PR China.E-mail: hhsyxp@163.com oxidation, etc.). ${ }^{8,9}$ Among these, sulfonation modification is the most efficient method. ${ }^{10,11}$ However, during the process of sulfonation modification, due to the reticular and condensed 3D structures of lignin, only the surface hydroxyl groups or ether functions was replaced by $\mathrm{SO}_{3} \mathrm{H}$ groups. Large number of sulfonate groups could not enter aliphatic side chain within lignin molecule, which results in high energy inputs, low yields and generate large number of organic waste. As a matter of fact, in order to break the recalcitrance of linkages in lignin, various processing techniques adopting harsh acidic or alkaline conditions ${ }^{12}$ and/or organic solvents such as tetrahydrofuran, ${ }^{13}$ propylene oxide, ${ }^{14}$ methanol. ${ }^{15}$ Obviously, these processes are generally less than ideal and economical, as a result of lack of environmental compatibility. ${ }^{16}$ Therefore a significant challenge remains on the achievement of an environmentally friendly, efficient, and cost effective method to break the linkages, thus to make the most of functional groups within lignin molecule.

Ionic liquids (ILs) are a class of substances composed of cations and anions that exist in the liquid state at or below $100{ }^{\circ} \mathrm{C}^{17}$ Nowadays, ILs has been vigorously investigated as a substitute of traditional solvent owing to its distinct performance such as highly conductivity, wide electrochemical window, neglectable vapor tension, special solubility and can been designed. ILs with sufficiently strong coordinative ability have been mainly used as solvents for natural polymers including lignin, ${ }^{18}$ cellulose,${ }^{19}$ starch and their derivatives.$^{20} \mathrm{ILS}$ are most commonly used to treat biomass, including 1-alkyl-3methylimidazolium-chloride ionic liquids $[\mathrm{Rmim}]^{+} \mathrm{X}^{-}(\mathrm{R}=$ 
allyl, butyl, and ethyl; $\mathrm{X}=$ chlorine, bromine and iodine), 1alkyl-3-methylimidazolium-acid ionic liquids $[\mathrm{Rmim}]^{+} \mathrm{X}^{-}(\mathrm{R}=$ butyl and ethyl; $\mathrm{X}=$ acetate and hydrogen sulfate), 1-butyl-3methylimidazolium tetrafluoroborate $\left([\mathrm{Bmim}]\left[\mathrm{BF}_{4}\right]\right)$ or 1-butyl3-methylimidazolium methyl sulfate acetate ([Bmim] $\left.\left[\mathrm{MeSO}_{4}\right]\right) .{ }^{18}$ The high melting point and high viscosity of chloride ionic liquids, relative to 1-alkyl-3-methylimidazolium-acid ionic liquids, greatly limits efficiency and thus limits applications. ${ }^{21}$ Carboxyl ionic liquids such as [Emim] [OAc] is prime candidates for this application because its high hydrogen bond basicity, low viscosity and can been commercialize. ${ }^{22,23}$ There are many researches about the dissolution behaviors of lignin in ILs. So far, however, little research has been reported on ILs could be used as mild pretreatment solvent for enhancing the sulfonated efficiency of alkali lignin.

Herein, [Emim][OAc] with lower viscosity and strong hydrogen bond basicity was used to pretreat lignin, meanwhile, could to break the reticular linkages in lignin. In this work, the dissolution and regeneration method was employed to pretreat lignin. And the aim of this work is to obtain an efficient and mild method to break the recalcitrance of lignin macromolecule, thus to improve the chemical reactivity of lignin molecule. To begins with, we investigated the solubility of native alkali lignin (AL) in [Emim] [OAc] and its influence factors, including moisture content of lignin, dissolving time and temperature. The apparent standard Gibbs energy change $\left(\Delta G^{\circ}\right)$, the standard apparent entropy change $\left(\Delta S^{\circ}\right)$, and the apparent standard enthalpy energy change $\left(\Delta H^{\circ}\right)$ of lignin in [Emim][OAc] solution were estimated by using the experimental solubility data. The results of FT-IR implied that [Emim][OAc] could considered as a physical solvent for lignin. The results of 31P-NMR analysis of RL demonstrated that [Emim] [OAc] treatment can produce significant increases in hydroxyl groups. Furthermore, the water solubility and sulfonated degree of RL were increased by $14.6 \%$ and $33.6 \%$, respectively. In general, the $[$ Emim] $[\mathrm{OAc}]$ pretreatment could provide a more green and efficient means to exploit the lignin than conventional methods. To the best of our knowledge, this is the first report on the [Emim] [OAc] was used as a mild pretreatment reagent to enhance the sulfonated efficiency of alkali lignin.

\section{Experimental}

\subsection{Materials and methods}

Eucalyptus chips were obtained from Huatai Paper Co. Ltd., China. The dried chips were cut into small pieces $(2-3 \mathrm{~cm})$. The main chemical components of the chips were measured by the TAPPI standards: cellulose $(45.41 \% \pm 2.17 \%(\mathrm{w} / \mathrm{w}))$, hemicellulose $(19.09 \% \pm 1.91 \%(\mathrm{w} / \mathrm{w}))$, and Klason lignin $(23.24 \% \pm$ $1.02 \%(\mathrm{w} / \mathrm{w}))$. The acid-precipitating method was used to isolate the dissolved lignin from the black liquor. The alkaline lignin with a diameter of about 100-200 $\mu \mathrm{m}$ was collected by filtration, followed by washing with distilled water, and then freeze-dried for $24 \mathrm{~h}$. Black liquor utilised for this study was produced by alkali sulfite pulping process. Briefly, the conditions are as follows: $\mathrm{Na}_{2} \mathrm{SO}_{3}=14 \mathrm{wt} \%, \mathrm{NaOH}=3.5 \mathrm{wt} \%, \mathrm{Na}_{2} \mathrm{SO}_{3} / \mathrm{NaOH}=4$ / 1 , liquor $/$ raw material $=5 / 1$, temperature $=180{ }^{\circ} \mathrm{C}$, cooking time $=120 \mathrm{~min}$. [Emim $][\mathrm{OAc}]$ was purchased from Shanghai
Chengjie Chemical Co., China. Other reagents were of analytical grade and used without further purification.

\subsection{The dissolution and regeneration of lignin}

Fig. 1 illustrates the successive dissolution and regeneration of lignin from [Emim] [OAc]. A certain amount of lignin and $10 \mathrm{~mL}$ of $[\mathrm{Emim}][\mathrm{OAc}]$ were added to a $50 \mathrm{~mL}$ glass flask. The system was stirred at the specified temperature under nitrogen until it became a stable suspension. The process of regeneration was: weighed lignin samples was added to the [Emim][OAc] and stirred at a certain temperature until completely dissolved. Then, $100 \mathrm{~mL}$ deionized water was added to terminate the dissolution. The system was stirred for $15 \mathrm{~min}$ to extract the lignin. The RL was obtained by centrifuged at $8000 \mathrm{rpm}$ for $15 \mathrm{~min}$, followed by thorough washing with deionized water. To avoid aggregation of lignin in the drying process, the sample was obtained by freeze-drying. ${ }^{18}$

\subsection{Characterization}

The FT-IR spectras of lignin were conducted on a VERTEX 70 (Bruker, German) in the range of $500-4000 \mathrm{~cm}^{-1}$ at resolution of $0.5 \mathrm{~cm}^{-1}$. The GPC analyses were performed using GPC-MALLS (DAWN HELEOS, Wyatt, USA) system consisting of a 50 MW GaAs laser. The wavelength of the laser was $658 \mathrm{~nm}$. Lignin samples were acetylated to improve the solubility in tetrahydrofuran solution before analyses. First, $100 \mathrm{mg}$ lignin was added to the $5 \mathrm{~mL}$ pyridine-acetic anhydride mixture $(1: 1, \mathrm{v} / \mathrm{v})$ and kept in a sealed container under nitrogen. Next, the container was protected from sunlight for 2 days at $25{ }^{\circ} \mathrm{C}$. The acetylated lignin was obtained after $100 \mathrm{~mL}$ ether was added. The acetylated lignin was collected by filtration, followed by washing with distilled water, and then vacuum drying at $35^{\circ} \mathrm{C}$. Finally, the dried samples were diluted with HPLC grade tetrahydrofuran to $5.0 \mathrm{mg} \mathrm{mL}{ }^{-1}$. Then the molecular weight of lignin including the weight-average molecular weight $\left(M_{\mathrm{w}}\right)$, the number-average molecular weight $\left(M_{\mathrm{n}}\right)$, were determined by gelatin chromatograph (GPC). The morphology of the surfaces of lignin was observed by a scanning

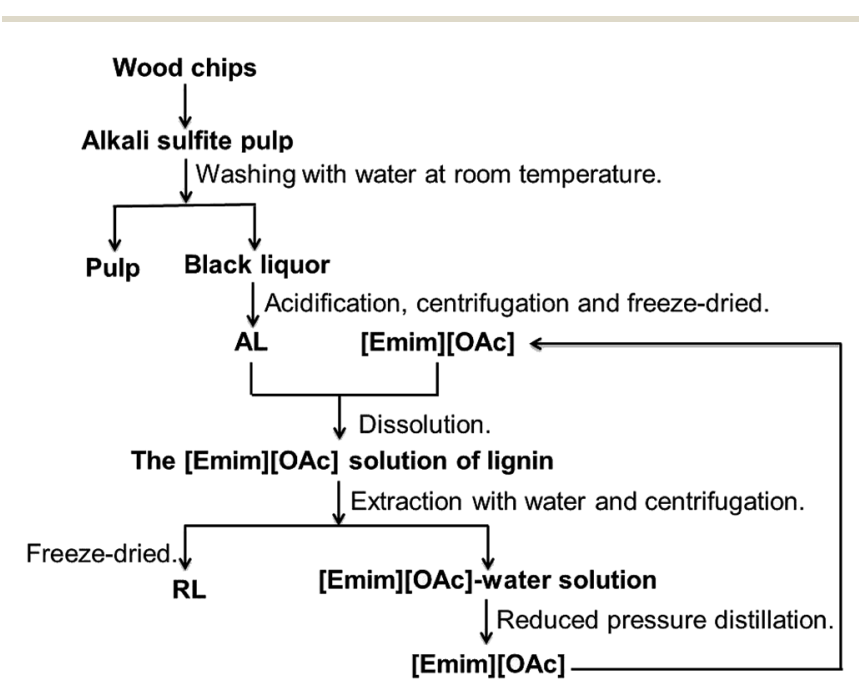

Fig. 1 Scheme for successive dissolution and regeneration of lignin in [Emim] [OAc]. 

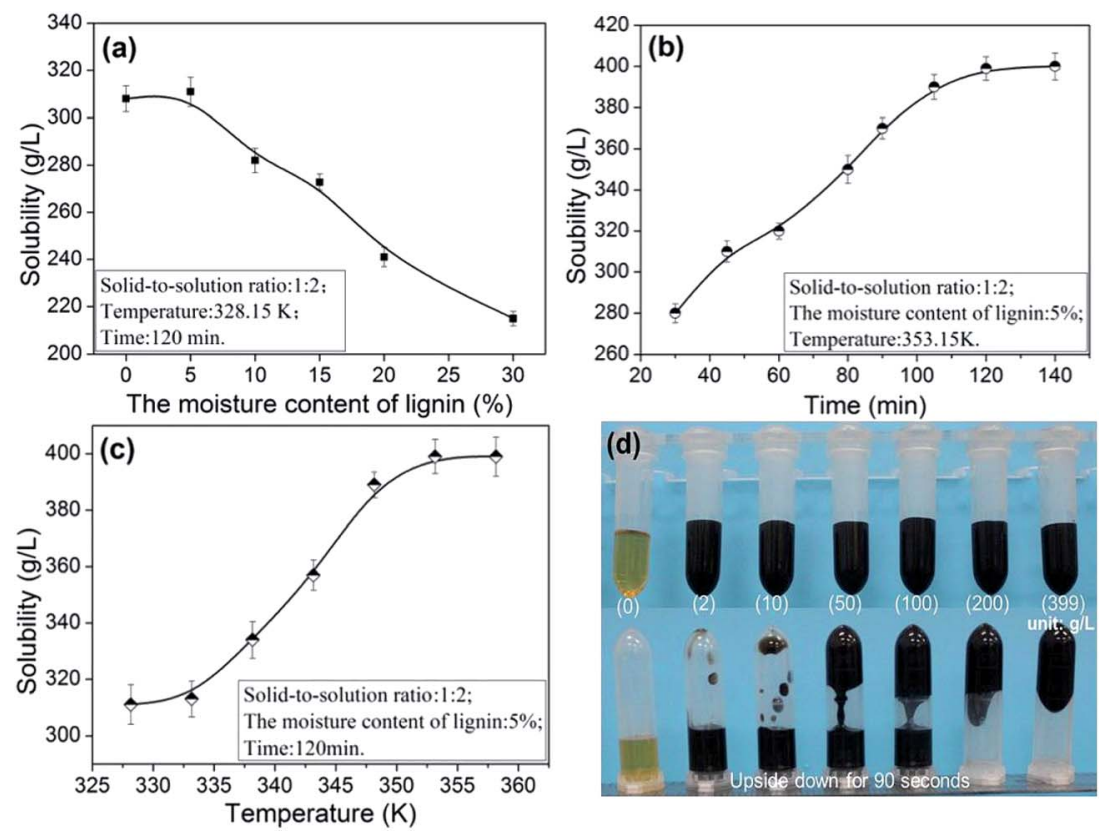

Fig. 2 Effects of moisture content (a), time (b), temperature (c) on the lignin solubility in [Emim] [OAc] and the photographs of solution with different concentration of lignin (d).

electron microscopy (SEM, Bruker, German) at $10 \mathrm{kV}$, using the following steps. A freeze dried sample was spread on a circular base and covered with a thin layer of gold $(\sim 2 \mathrm{~nm})$ by sputtering to promote conductivity before SEM observation. To further characterize the structural changes, lignin before and after dissolution was investigated by ${ }^{31} \mathrm{P}-\mathrm{NMR}$ spectroscopy. The Bruker Advance III $400 \mathrm{MHz}$ spectrometer operating at a frequency of $100.6 \mathrm{MHz}$ was employing to record the 31P-NMR spectras of samples. Approximately, $40 \mathrm{mg}$ lignin and $400 \mu \mathrm{L}$ deuterated pyridine were added to a $2 \mathrm{~mL}$ colorimetric tube and the weight of lignin was recorded. $250 \mu \mathrm{L} \mathrm{CDCl}_{3}$ was added until the lignin dissolved fully. $80 \mathrm{mg} \mathrm{mL}{ }^{-1} \mathrm{CDCl}_{3}$-deuterated pyridine $(1.6: 2, \mathrm{v} / \mathrm{v}), 11 \mathrm{mg} \mathrm{mL}^{-1} \mathrm{CDCl}_{3}$-deuterated pyridine $(1.6: 1, \mathrm{v} / \mathrm{v})$ and $100 \mu \mathrm{L}$ organ phosphorus reagents were added. ${ }^{25}$ The thermal stability of the dried lignin was examined with thermogravimetric analysis (Q500, USA). Briefly, $15 \mathrm{mg}$ lignin were treated to $700{ }^{\circ} \mathrm{C}$ at a heating rate of $20^{\circ} \mathrm{C} \mathrm{min}^{-1}$ under nitrogen. The nitrogen flow rate was $30 \mathrm{~mL} \mathrm{~min}{ }^{-1}$.

\subsection{Sulfonation reaction}

Sulfonated degrees were significantly affected by conditions. In this study, sulfonation of lignin before and after ILs pretreatment is carried out under the experimental conditions, as mentioned in the Amel's and Ouyang's researchs. ${ }^{10,24}$ The sulfonation degree of sulfonated AL and sulfonated RL were tested by conductometric titration method. ${ }^{25}$

\section{Results and discussion}

\subsection{Lignin dissolution}

3.1.1. The dissolution properties of lignin. The performance of ILs was significantly affected by water molecules. Specifically, the presence of water reduces the ILs dissolution efficiency while simultaneously maintaining the internal hydrogen bonding. ${ }^{26}$ The effect of moisture content on the lignin solubility in [Emim] $]$ OAc] was shown in Fig. 2a.

As proposed by Tian et al. and Lateef et al., the possible dissolution mechanism of lignin in ILs involves the $\mathrm{OH}$ groups of lignin. ${ }^{27,28}$ Lateef $e t$ al. reported in their work that ILs could interact with terminal $\mathrm{OH}$ groups of lignin, subsequently disrupting the internal network within the lignin molecule, resulting in the dissolution of lignin. The anion and cation of ILs played key roles in lignin dissolution. As shown in the Fig. 3, the oxygen atoms in $\mathrm{OH}$ groups of lignin serve as electron donor, while the hydrogen atoms act as an electron acceptor. And the $[\mathrm{Emim}]^{+}$in $[\mathrm{Emim}][\mathrm{OAc}]$ solvents could be seen as electron acceptor center and $[\mathrm{OAc}]^{-}$as electron-donor center. When ionic liquid and terminal $\mathrm{OH}$ groups of lignin were located close enough and to form interaction, the internal network within the lignin molecule were breaked, and, finally, the lignin dissolves. ${ }^{28}$ In similar circumstances, the oxygen in moisture is also considered to be as electron donor. The hydrogen atoms were regarded as an electron acceptor. When the moisture content of lignin was higher, due to the competitions among the lignin atoms and water, the dissolving ability was reduced greatly. As can been seen from the Fig. 2a, when the moisture content was increased from 5 to $30 \%$, the solubility of lignin decreased from 311.1 to $215.5 \mathrm{~g} \mathrm{~L}^{-1}$. In addition, the dissolution speed is significantly influenced by the viscosity of the ionic liquids. ${ }^{29}$ The possible reason was that small amounts of moisture in lignin reduced the viscosity of [Emim] [OAc]. It would be advantageous for two centers could be located close enough, thus to improve the dissolving ability of ionic liquid. When the moisture content was $5 \%$, the solubility reached maximum values of $311.1 \mathrm{~g} \mathrm{~L}^{-1}$. 


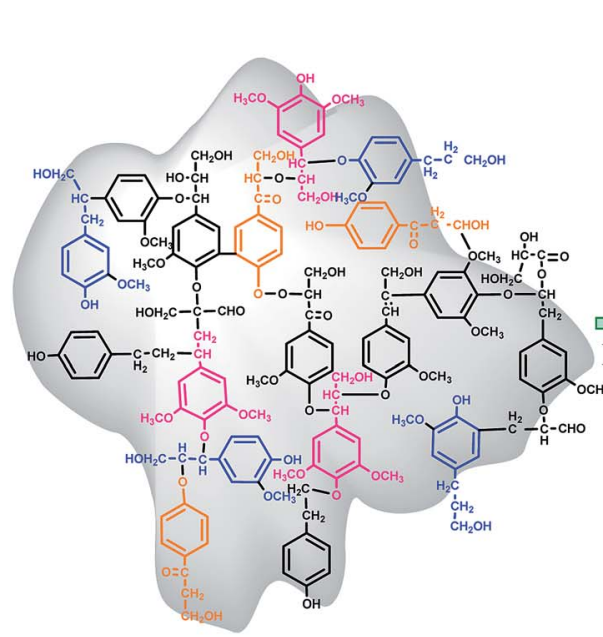

AL

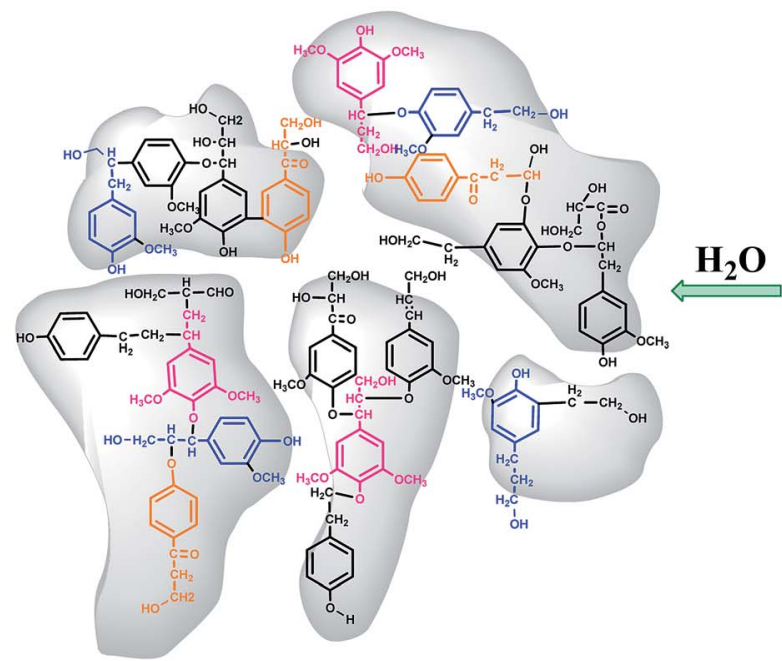

$\mathbf{R L}$
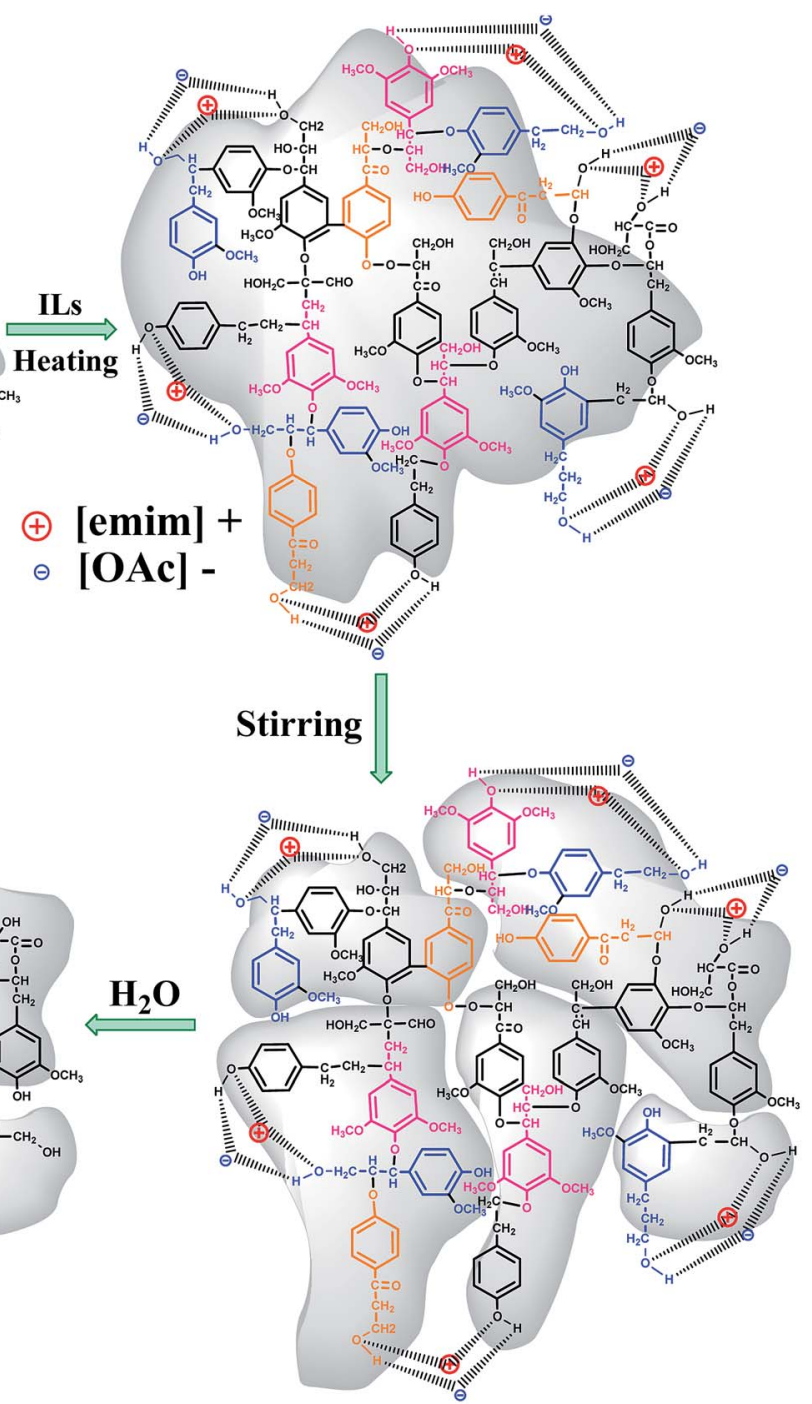

Fig. 3 Possible dissolution mechanism of lignin in [Emim] [OAc].

The effect of time on the solubility of lignin was showed in Fig. 2b. When the time was increased, the solubility increased substantially. The dissolution rate goes up rapidly at the beginning as the time increased. And when the time was $120 \mathrm{~min}$, the solubility reaches $399.0 \mathrm{~g} \mathrm{~L}^{-1}$. As shown in the Fig. 2c, when the temperature was increased from 328.15 to $353.15 \mathrm{~K}$, the solubility of lignin increased from to $399.0 \mathrm{~g} \mathrm{~L}^{-1}$, and was stable at about $358.15 \mathrm{~K}$. In sum, the optimal conditions of dissolution were as follows: moisture content of lignin was $5 \%, 353.15 \mathrm{~K}$ and $120 \mathrm{~min}$, for which a higher solubility (399.0 $\left.\mathrm{g} \mathrm{L}^{-1}\right)$ of lignin in [Emim][OAc] was obtained. The content of lignin significantly affects the viscosity of solution. As can be seen from Fig. 2d, with the increasing of lignin content, the solution became increasingly thick, and the mobility gradually decreased. When the solubility reached $399 \mathrm{~g} \mathrm{~L}^{-1}$, the stability of solution can be maintained for about 90 seconds at room temperature. In order to confirm that the lignin samples was completely dissolved in ionic liquid, the changes of lignin during the dissolution process were monitored by the polarizing microscope. And the dissolution behaviors of lignin in [Emim] [OAc] were shown in the Fig. 4. In the initial dissolution process, lignin with fiber structure could be seen clearly under the polarizing microscope (Fig. 4a, arrow). Because the recalcitrance and stable structure of lignin, complete dissolution was difficult to achieve within a short time. When the dissolving time was increased to $20 \mathrm{~min}$, most lignin was dissolved and only a small handful of samples were present, as shown in the Fig. 4b. Moreover, the complete dissolution of lignin was obtained at $120 \mathrm{~min}$, and the eyeshot became yellow (Fig. 4d).

3.1.2. Thermodynamic functions of solution. In recent thermodynamic treatments, the following modified van't Hoff expression was employed to calculate the apparent standard enthalpy change in solution ${ }^{\mathbf{3 0 , 3 1}}$ and the value can be obtained as the following formula:

$$
\left[\partial \ln \chi / \partial\left(1 / T-1 / T_{\mathrm{hm}}\right)\right]_{\mathrm{P}}=-\Delta H^{\circ} / R
$$




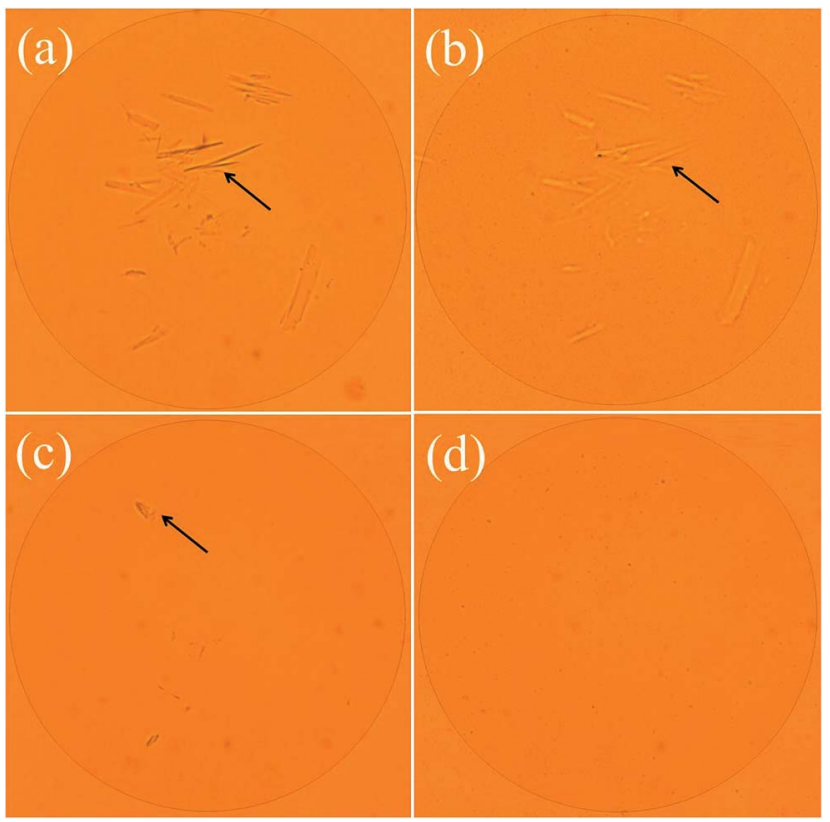

Fig. 4 PLM images of lignin dissolved in [Emim] [OAc] at $353.15 \mathrm{~K}$ for $0 \mathrm{~min}(\mathrm{a}), 20 \mathrm{~min}$ (b), $60 \mathrm{~min}$ (c), $120 \mathrm{~min}$ (d).

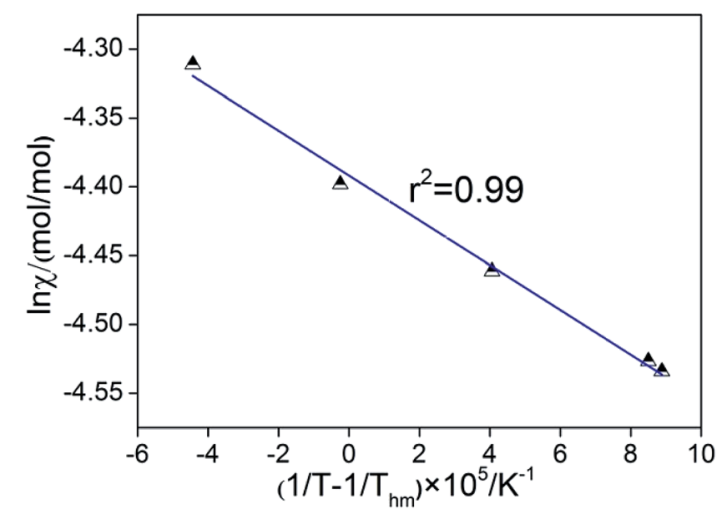

Fig. 5 Plots of $\left(1 / T-1 / T_{\mathrm{hm}}\right)$ against $\ln \chi$.

Table 1 The thermodynamic functions related to solution process at pressure $P=0.1 \mathrm{MPa}$

\begin{tabular}{llllll}
\hline$r^{2}$ & $K$ & $T_{\mathrm{hm}} / \mathrm{K}$ & $\begin{array}{l}\Delta G^{\circ} / \\
\left.(\mathrm{kJ} \mathrm{mol})^{-1}\right)\end{array}$ & $\begin{array}{l}\Delta H^{\circ} / \\
\left(\mathrm{kJ} \mathrm{mol}^{-1}\right)\end{array}$ & $\begin{array}{l}\Delta S^{\circ} / \\
\left(\mathrm{J} \mathrm{mol}{ }^{-1} \mathrm{~K}^{-1}\right)\end{array}$ \\
\hline 0.9921 & -1628.02 & 338.00 & 12.34 & 15.34 & 3.55
\end{tabular}

In eqn (1), $\Delta H^{\circ} / R$ represents the apparent standard enthalpy energy change, $\chi$ is the solute solubility in mole fraction, and harmonic mean of the experimental temperatures $\left(T_{\mathrm{hm}}\right)$ could be calculated according to the following equation:

$$
T_{\mathrm{hm}}=n / \sum_{i=1}^{n} \frac{1}{T_{i}}
$$

In eqn (2), $n$ represents the number of temperatures, thus, we can calculate the value of $T_{\mathrm{hm}}$ as follows:

$$
\begin{aligned}
T_{\mathrm{hm}} & =5 / \sum_{i=1}^{5} \frac{1}{T_{i}}=5 /(1 / 328.15+\ldots+1 / 348.15) \mathrm{K} \\
& =338.00 \mathrm{~K} .
\end{aligned}
$$

The apparent standard Gibbs energy change $\left(\Delta G^{\circ}\right)$ at $T_{\mathrm{hm}}$ could be calculated by:

$$
\Delta G^{\circ}=-R \times T_{\mathrm{hm}} \times K
$$

As proposed by Krug et al., one plot is made with $(1 / T-1$ / $T_{\mathrm{hm}}$ ) as ordinate and $\ln \chi$ as abscissas, as shown in Fig. 5 . It is very obvious that the linear relations between $\left(1 / T-1 / T_{\mathrm{hm}}\right)$ and $\ln \chi$ are obtained and the value of linear correlation coefficient $\left(r^{2}\right)$ for the solution process was higher than 0.99, which indicates that the van't Hoff equation is useful to figure out the enthalpies of solution. ${ }^{32}$ The values of $K$ can be calculated from the intercept of the line as shown in Table 1.

The standard apparent entropy change $\left(\Delta S^{\circ}\right)$ could be calculated according to the following equation:

$$
\Delta S^{\circ}=\left(\Delta H^{\circ}-\Delta G^{\circ}\right) / T_{\mathrm{hm}}
$$

The solution process apparently is not spontaneous and endothermic could be inferred from the value of $\Delta G^{\circ}$. Furthermore, the value of $\Delta S^{\circ}$ and $\Delta H^{\circ}$ were positive, which also indicated that the solution process is endothermic and entropy increment.

\subsection{Lignin characterization}

3.2.1. FT-IR analysis. FT-IR spectras were used to identify the functional groups of the AL and RL (Fig. 6). As shown in the spectrums the characteristic absorbance bands at 3400, 2840 and $2490 \mathrm{~cm}^{-1}$ could be attributed to $\mathrm{OH}$, methoxyl and aliphatic $\mathrm{CH}$, respectively. The characteristic FT-IR peaks located at $1595 \mathrm{~cm}^{-1}$ can be attributed to benzene skeleton vibration and $\mathrm{C}=\mathrm{O}$ stretching vibration. The peak at 1507

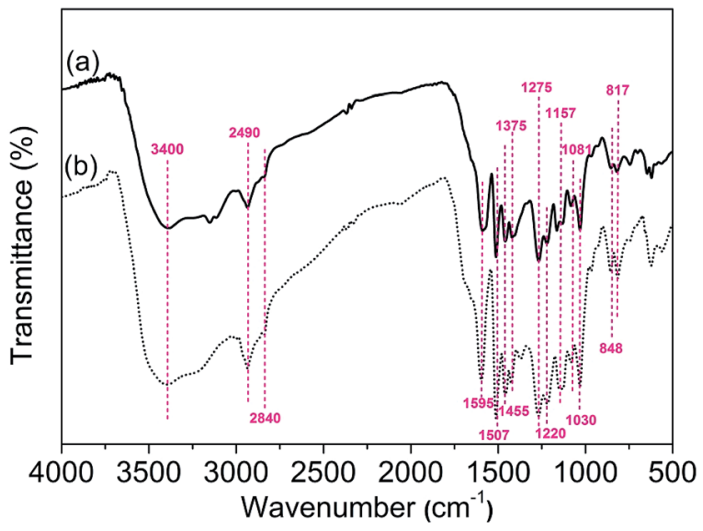

Fig. 6 FT-IR spectras of AL (a) and RL (b); the [Emim][OAc] pretreatment was conducted at a moisture content of lignin was $5 \%$ for $120 \mathrm{~min}$ at $353.15 \mathrm{~K}$. 
$\mathrm{cm}^{-1}$, which corresponds to benzene skeleton vibration. Meanwhile, the peaks at $1375 \mathrm{~cm}^{-1}$ and $1275 \mathrm{~cm}^{-1}$, which indicated that lignin contains Syringyl and Guaiacyl units. ${ }^{33,34}$ Other bands at 855 and $817 \mathrm{~cm}^{-1}$ represent lone aryl $\mathrm{CH}$ wags and two-adjacent aryl $\mathrm{CH}$ wags, respectively. The band at 2840 $\mathrm{cm}^{-1}$ and $1030 \mathrm{~cm}^{-1}$ could be attributed to the symmetric $\mathrm{CH}_{3}$ stretch of the methoxyl group and the $\mathrm{C}-\mathrm{O}$ stretch for the $\mathrm{O}-$ $\mathrm{CH}_{3}$ and $\mathrm{C}-\mathrm{OH}$, respectively. ${ }^{35}$ A comparison of the samples revealed that minor chemical changes occurred during dissolving process. ${ }^{36}$

3.2.2. GPC analysis. The MWD of the lignin samples were listed in Table 2. As can be seen from the Table 2, the numberaverage molecular weight $\left(M_{\mathrm{n}}\right)$ and weight-average molecular weight $\left(M_{\mathrm{w}}\right)$ of $\mathrm{AL}$ before ionic liquids treatment was 2769 and $4753 \mathrm{~g} \mathrm{~mol}^{-1}$, respectively. Nevertheless, the $M_{\mathrm{n}}$ and $M_{\mathrm{w}}$ of RL was

Table 2 Distribution of lignin molecular weight ${ }^{a}$

\begin{tabular}{lll}
\hline Sample ID & $M_{\mathrm{n}}\left(\mathrm{g} \mathrm{mol}^{-1}\right)$ & $M_{\mathrm{w}}\left(\mathrm{g} \mathrm{mol}^{-1}\right)$ \\
\hline AL & 2769 & 4753 \\
RL & 1796 & 2931
\end{tabular}

${ }^{a} M_{\mathrm{n}}=$ number-average molecular weight; $M_{\mathrm{w}}=$ weight-average molecular weight.
1796 and 2931, respectively. The molecular weight of AL was higher than that of RL. From the molecular weight, it was found that RL is a more depolymerized lignin. ${ }^{37}$ Moreover, little change in polydispersity index was observed. Lignin with larger $M_{\mathrm{w}}$ was decomposed to compound of small molecular weight during the dissolving processes, which help to narrow the molecular weight distribution. As proposed by Eriksson et al., ${ }^{38}$ lignin with low molecular weight was easy to be degraded as compared with high molecular weight lignin. Consequently, the decreased of molecular weight after ionic liquids treatment was beneficial to realize the degradation and transformation of lignin. ${ }^{38}$

3.2.3. ${ }^{31} \mathrm{P}-\mathrm{NMR}$ analysis. The spectras of ${ }^{31} \mathrm{P}-\mathrm{NMR}$ clearly shown the major hydroxyl groups in lignin samples were from aliphatic regions (Fig. 7). ${ }^{39}$ As seen from Table 3, the hydroxyl group of aliphatic, condensed phenolic, $p$-hydroxy-phenyl and guaiacyl in the samples fragments could be recognized by the peaks in the regions $\delta 150.0-145.0, \delta 144.6-143.6, \delta 138.6-137.0$ and ס140.2-138.6 ppm, respectively. ${ }^{40,41}$ Compared with AL, these results of RL represent increases by $27.18 \%, 14.39 \%, 50 \%$ and $25.79 \%$, respectively. And the increase of hydroxyl group of RL was beneficial to improve the reactivity towards some reagent such as formaldehyde. ${ }^{22}$ The content of carboxylic hydroxyl in RL $\left(0.76 \mathrm{mmol} \mathrm{g}^{-1}\right)$ was lower than the untreated lignin $(1.08 \mathrm{mmol}$ $\left.\mathrm{g}^{-1}\right)$. It was observed that after pretreatment, there was a significant decrease in guaiacyl and condensed phenolic units. ${ }^{43}$

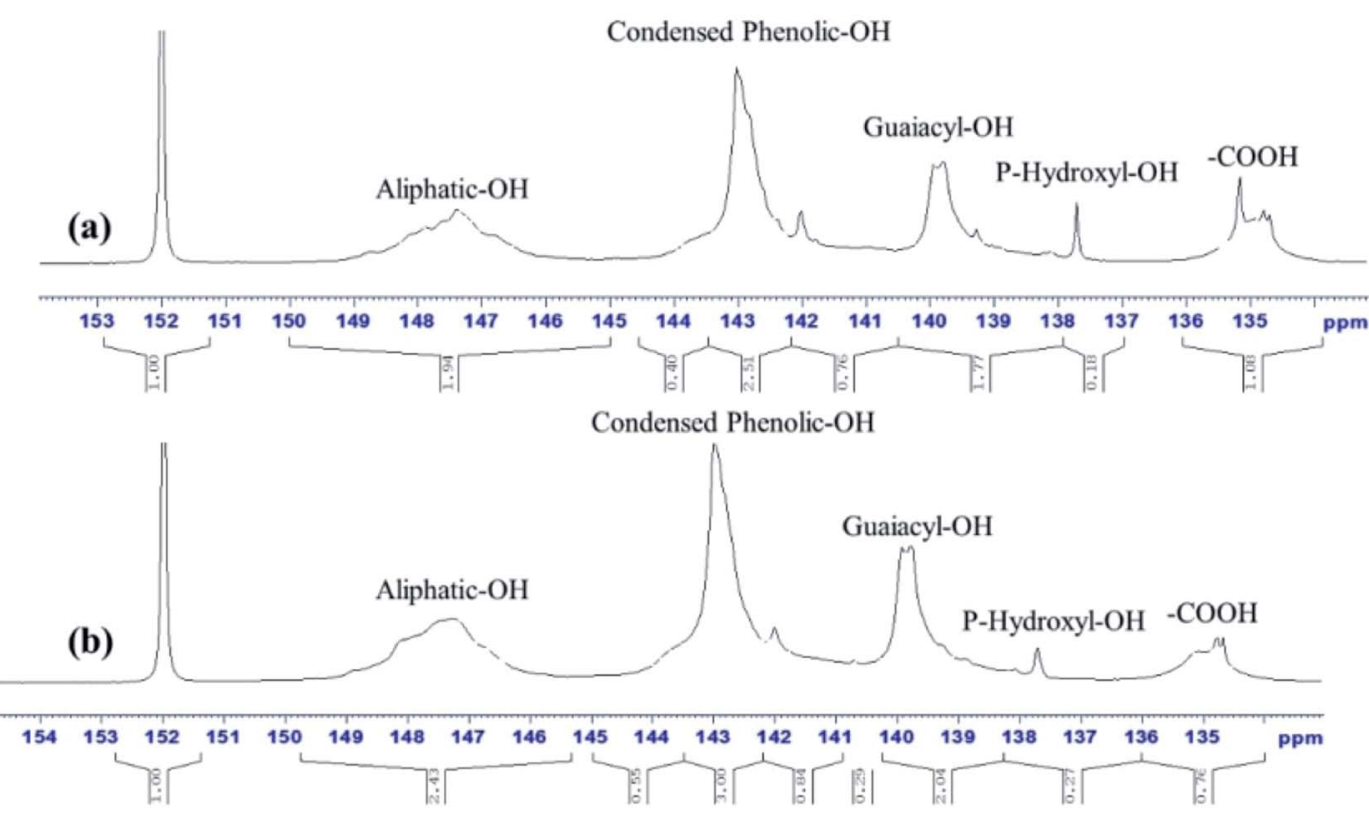

Fig. $7{ }^{31} \mathrm{P}-\mathrm{NMR}$ spectras of $\mathrm{AL}$ (a) and RL (b); the [Emim] [OAc] pretreatment was conducted at a moisture content of lignin was $5 \%$ for 120 min at $353.15 \mathrm{~K}$.

Table 3 Hydroxyl group contents in lignin samples calculated from quantitative ${ }^{31} \mathrm{P}-\mathrm{NMR}$ spectra $\left(\mathrm{mmol} \mathrm{g}^{-1}\right)$

\begin{tabular}{lllll}
\hline Samples ID & $\begin{array}{l}\text { Aliphatic } \\
\text { OH }\end{array}$ & $\begin{array}{l}\text { Condensed phenolic } \\
\text { OH }\end{array}$ & $\begin{array}{l}\text { Guaiacyl and } \\
\text { demethylate }-\mathrm{OH}\end{array}$ & \multicolumn{2}{c}{$\begin{array}{l}\text {-Hydroxy-phenyl } \\
\text { OH }\end{array}$} \\
\hline AL & 1.95 & 1.32 & 1.59 & 0.18 \\
RL & 2.48 & 1.51 & 2.0 & 0.27
\end{tabular}




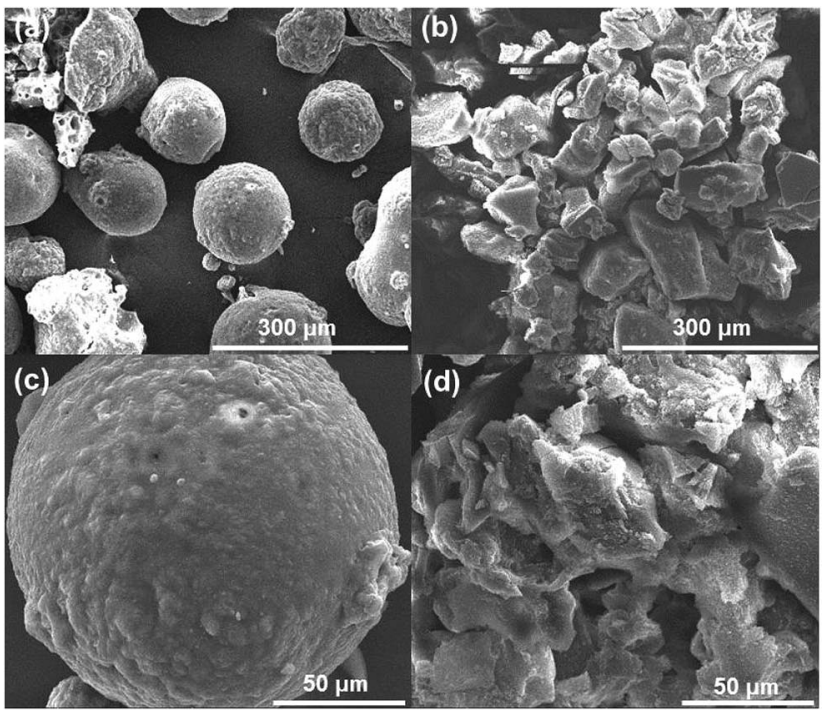

Fig. 8 SEM images of $A L(a$ and $c$ ) and RL (b and d); the [Emim] [OAc] pretreatment was conducted at a moisture content of lignin was $5 \%$ for $120 \mathrm{~min}$ at $353.15 \mathrm{~K}$

3.2.4. SEM analysis. The structure of lignin before and after dissolution was investigated from SEM images. AL has regular spherical structure with smooth surface, and the average particle size of the particles was about $150 \mu \mathrm{m}$ calculated from SEM images (Fig. 8a and c). The potential reason for such morphology: The lignin was concentrated from black liquors, because of their surface tension, a thermodynamically more stable form-spherical was taken. ${ }^{44}$ In contrast, the spherical structure of RL was not observed (Fig. $8 \mathrm{~b}$ and d). Instead, the RL was polygonal in shape with multiple conchoidal fractures. ${ }^{37}$ One possible explanation for this is that in the dissolving process, [Emim] $[\mathrm{OAc}]$ penetrated into the lignin network and resulted in more deformed macroscopic structures.

3.2.5. TGA and DTG analysis. The TGA and DTG curves of the freeze-dried lignin samples are shown in Fig. 9. In the first stage (I), neglect small initial drops in weight occurring near $100{ }^{\circ} \mathrm{C}$ because of evaporation of retained moisture from the samples. During the main degradation stage (II and IV), the thermal properties of AL and RL indicated that all of the lignin presented the same degradation pattern. For the AL, the range
Table 4 Rage of maximum of thermal decomposition temperature $\left(T_{\text {max }}\right)$, temperature at maximum rate of wt loss $\left({ }^{\circ} \mathrm{C}\right)$ and unvolatilized weight fraction at $700{ }^{\circ} \mathrm{C}$ (residue)

\begin{tabular}{llll}
\hline $\begin{array}{l}\text { Samples } \\
\text { ID }\end{array}$ & $\begin{array}{l}\text { Range of } \\
T_{\max }\left({ }^{\circ} \mathrm{C}\right)\end{array}$ & $\begin{array}{l}\text { Temperature at } \\
\text { maximum rate of wt loss }\left({ }^{\circ} \mathrm{C}\right)\end{array}$ & $\begin{array}{l}\text { Residue } \\
(\%)\end{array}$ \\
\hline $\mathrm{AL}$ & $240-570$ & 364.93 & 36.49 \\
$\mathrm{RL}$ & $220-550$ & 358.26 & 32.87
\end{tabular}

of maximum decomposition rate temperature $\left(T_{\max }\right)$ was about 240-570 ${ }^{\circ} \mathrm{C}$, while the range of the $T_{\max }$ of RL was about $220-$ $550{ }^{\circ} \mathrm{C}$. Thermal degradation in this range was the result of the fragmentation of inter-unit linkages. Some monomeric phenols produced by pyrolytic degradation were released into the vapour phase. At last stage, the TGA curves were becoming flattened. After heating to $700{ }^{\circ} \mathrm{C}$, due to the formation of aromatic structures which was highly condensed, two samples still remain unvolatilized. ${ }^{34}$

Thermal characteristics of lignin before and after ionic liquids treatment was presented in Table 4. The TGA and DTG analysis results indicate that the thermostability of RL was slightly lower the lignin. The difference in the stability of the two lignins could be due to the difference in their noncovalent interactions, such as hydrogen bonding as well as in the detailed physical structures. ${ }^{45}$

3.2.6. Effects of number of recycles. The key to realize the efficiency and environmentally friendly biomass processing is the solvent can be easily recovered without losing its extraction efficiency. To verify this, the effects of number of recycles on the solubility and dissolution efficiency were examined. The ionic liquids were recovered through reduced pressure distillation at $60{ }^{\circ} \mathrm{C}$ and $150 \mathrm{kPa}$ for $30 \mathrm{~min}$. The rate of recovery of [Emim] [OAc] was more than $98.5 \%$, which demonstrated that the [Emim][OAc] was a good recyclable lignin solvent. As shown in the Fig. 10a, when the numbers of recycles were increased from 1 to 5 , the solubility and dissolution efficiencies decreased slightly. When the number of recycles was 5 , the solubility and dissolution efficiencies were $330.0 \mathrm{~g} \mathrm{~L}^{-1}$ and $82.72 \%$, respectively. Compared to the pure $[\mathrm{Emim}][\mathrm{OAc}]$, the dissolution efficiencies were decreased $17.28 \%$. The possible reason for decline of dissolution efficiencies was due to the water in the
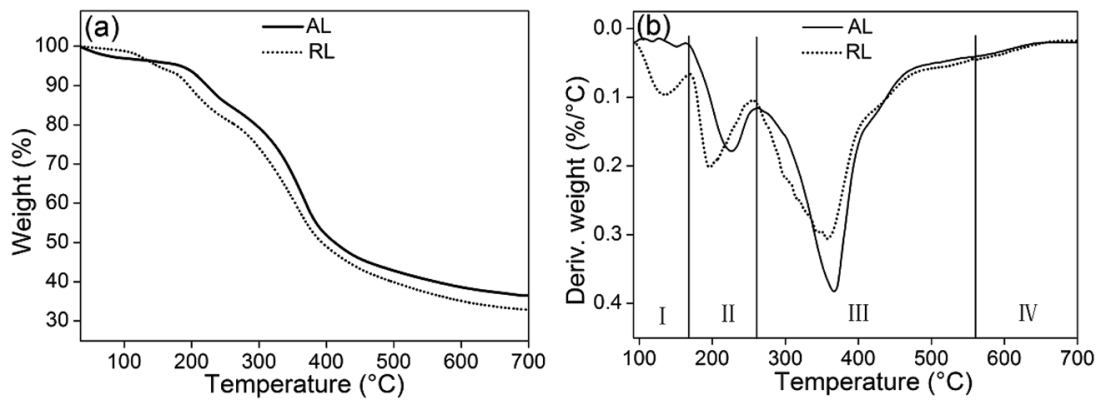

Fig. 9 TGA (a) and DTG (b) curves of AL and RL; the [Emim] [OAc] pretreatment was conducted at a moisture content of lignin was $5 \%$ for 120 min at $353.15 \mathrm{~K}$ 

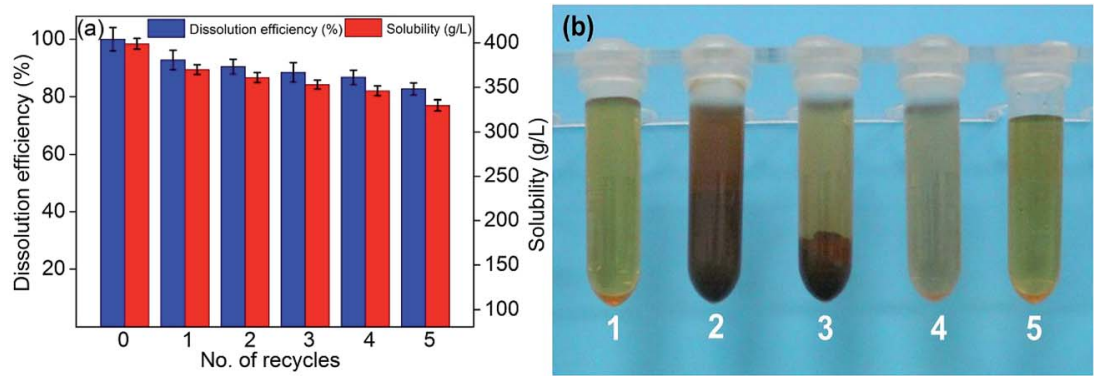

Fig. 10 (a) Effects of number of recycles on the solubility and dissolution efficiency, and (b) the images of pure [Emim][OAc] (1), regenerated solutions (2), regenerated solutions after centrifugation (3), [Emim][OAc]-water solution (4), and recyclable [Emim] [OAc] (5).

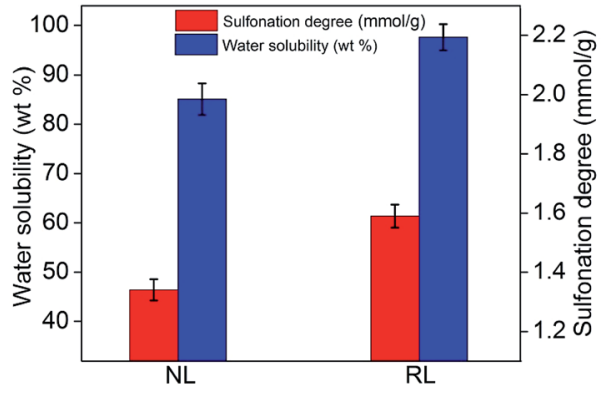

Fig. 11 Properties of the sulfonated $\mathrm{AL}$ and $\mathrm{RL}$; the [Emim][OAC] pretreatment was conducted at a moisture content of lignin was $5 \%$ for $120 \mathrm{~min}$ at $353.15 \mathrm{~K}$; the sulfonation reaction was conducted at an $\mathrm{HCHO}$ dosage of $15 \mathrm{wt} \%, \mathrm{Na}_{2} \mathrm{SO}_{3}$ dosage of $30 \mathrm{wt} \%$ at $80{ }^{\circ} \mathrm{C}$ for $2 \mathrm{~h}$.

solvent. ${ }^{46}$ With the addition of deionized water, the dissolved lignin precipitates out. As can be seen from Fig. 10b, the RL could be easily recycled by centrifugation. And the ionic liquids were recovered through reduced pressure distillation. It can be seen from Fig. 10b-5 that, compared to the pure solvent, the color of recyclable [Emim][OAc] was slightly increased. The increase of color was due to the tiny amounts of lignin in solvent.

\subsection{Properties of the sulfonated lignin}

Favorable water solubility and sufficient number of sulfonic groups is important for expanding the fields of lignin application. This can be achieved through sulfonation or hypomethylation. The sulfonation reaction mechanism can be generalized: the $-\mathrm{SO}_{3} \mathrm{H}$ groups enter the aliphatic side chain of lignin molecule and the hydroxyl or ether functions at the $\alpha$ carbon of the phenyl propane unit was replaced by these $-\mathrm{SO}_{3} \mathrm{H}$ groups. For hypomethylation, during the process of reaction, sulfite reacting with formaldehyde to produce $-\mathrm{CH}_{2} \mathrm{SO}_{3} \mathrm{H}$ groups, which bonded to the aromatic nuclei of the lignin molecule. ${ }^{47}$ Besides that, because of excess of sulfite, $-\mathrm{SO}_{3} \mathrm{H}$ groups could be introduced into aliphatic side chain of the lignin molecule. As can been seen from the reaction mechanism, having a sufficient number of hydroxyl groups or ether functions is critical for sulfonation or hypomethylation reaction. Sulfonated degrees can be determined by water solubility, the molar weight distribution as well as the hydrophilic character. Fig. 11 shows the properties of the sulfonated lignin before and after [Emim][OAc] treatment. The water solubility of sulfonated RL was $97.5 \mathrm{wt} \%$, which increased about $14.6 \%$ compared to that of sulfonated AL. The sulfonated degree of RL was $1.79 \mathrm{mmol} \mathrm{g}^{-1}$, which also increased nearly $33.6 \%$ compared to that of sulfonated AL. The improvement in water solubility and sulfonated degree demonstrated that [Emim] [OAc] can break the linkages in lignin molecule, improve the sulfonation efficiency, and expand the fields of lignin application.

\section{Conclusion}

In this study, [Emim][OAc] was elected as novel pretreatment solvent for enhancing the sulfonated efficiency of alkali lignin. The pretreatment process not only is simple and rapid but also has no requirement of any pretreatment. The FT-IR and ${ }^{13} \mathrm{P}$ NMR analysis of RL indicated [Emim][OAc] was a good direct solution without any derivatization. Furthermore, the lower molecular weight was obtained when lignin is regenerated from ionic liquid and this will beneficial to realize the degradation and transformation of lignin. In addition, the [Emim][OAc] were easily recovered through reduced pressure distillation and the dissolution efficiencies maintained $\sim 92 \%$ after 1 cycle and $\sim 82 \%$ after 5 cycles. Importantly, when the [Emim][OAc] pretreatment was conducted at a moisture content of lignin was $5 \%$ for $120 \mathrm{~min}$ at $353.15 \mathrm{~K}$, high sulfonated efficiency was achieved. The water solubility and sulfonated degree of RL were increased by $14.6 \%$ and $33.6 \%$, respectively. Considering the low-cost and environmentally friendly of [Emim][OAc], this method could provides a simple and green method to realize the high-value utilization of biomass.

\section{Acknowledgements}

The authors are grateful for the financial support afforded by 111 Plan and Guangdong Provincial Science \& Technology Plan Projects (No. 2015B020241001); The State Key Laboratory of Pulp and Paper Engineering (No. 2015ZD04); Open Foundation of Zhejiang Provincial Key Lab. for Chem. \& Bio. Processing Technology of Farm Products and Zhejiang Provincial Collaborative Innovation Center of Agricultural Biological Resources Biochemical Manufacturing (No. 2016KF0201). 


\section{Notes and references}

1 W. Liu, R. Zhou, D. Zhou, G. Ding, J. M. Soah, C. Y. Yue and X. Lu, Carbon, 2015, 83, 188-197.

2 J. Zhang, Y. Chen and M. A. Brook, ACS Sustainable Chem. Eng., 2014, 2, 1983-1991.

3 H. F. Mark, Encyclopedia of polymer science and technology, concise, John Wiley \& Sons, 2013.

4 X. Guo, S. Zhang and X. Shan, J. Hazard. Mater., 2008, 151, 134-142.

5 R. J. A. Gosselink, M. B. Snijder, A. Kranenbarg, E. R. P. Keijsers, E. De Jong and L. Stigsson, Ind. Crops Prod., 2004, 20, 191-203.

6 J. Zakzeski, P. C. A. Bruijnincx, A. L. Jongerius and B. M. Weckhuysen, Chem. Rev., 2010, 110, 3552-3599.

7 L. D. C. Sousa, M. Jin, S. P. S. Chundawat, V. V. Bokade, X. Tang, A. Azarpira, F. Lu, U. Avci, J. F. Humpula and N. Uppugundla, Energy Environ. Sci., 2016, 9, 1215-1223.

8 S. Wu and H. Zhan, Cellul. Chem. Technol., 2001, 35, 253-262. 9 M. V. Alonso, M. Oliet, F. Rodriguez, J. Garcia, M. A. Gilarranz and J. J. Rodriguez, Bioresour. Technol., 2005, 96, 1013-1018.

10 X. Ouyang, L. Ke, X. Qiu, Y. Guo and Y. Pang, J. Dispersion Sci. Technol., 2010, 30, 1-6.

11 Y. Matsushita and S. Yasuda, Bioresour. Technol., 2005, 96, 465-470.

12 D. Ciolacu, A. M. Oprea, N. Anghel, G. Cazacu and M. Cazacu, Mater. Sci. Eng., C, 2012, 32, 452-463.

13 Y. Li, M. Wu, B. Wang, Y. Wu, M. Ma and X. Zhang, ACS Sustainable Chem. Eng., 2016, 4, 5523-5532.

14 Y. Uraki, T. Imura, T. Kishimoto and M. Ubukata, Carbohydr. Polym., 2004, 58, 123-130.

15 H. Yamamoto, M. Amaike, H. Saitoh and Y. Sano, Mater. Sci. Eng., C, 1999, 7, 143-147.

16 S. Wu and D. S. Argyropoulos, J. Pulp Pap. Sci., 2003, 29, 235240.

17 C. M. Gordon, Appl. Catal., A, 2001, 222, 101-117.

18 Y. Sun, J. Xu, F. Xu, R. Sun and G. L. Jones, RSC Adv., 2013, 4, 2743-2755.

19 S. Zhu, Y. Wu, Q. Chen, Z. Yu, C. Wang, S. Jin, Y. Ding and G. Wu, Green Chem., 2006, 8, 325-327.

20 Q. Liu, M. H. A. Janssen, F. Van Rantwijk and R. A. Sheldon, Green Chem., 2005, 7, 39-42.

21 E. Turner, C. C. Pye and R. D. Singer, J. Phys. Chem. A, 2003, 107, 2277-2288.

22 P. Bonhote, A. Dias, N. Papageorgiou, K. Kalyanasundaram and M. Gratzel, Inorg. Chem., 1996, 35, 1168-1178.

23 F. Hermanutz, F. Gahr, E. Uerdingen, F. Meister and B. Kosan, Macromol. Symp., 2008, 262, 23-27.
24 A. Kamoun, A. Jelidi and M. Chaabouni, Cem. Concr. Res., 2003, 33, 995-1003.

25 O. Straněl and T. Sebok, Cem. Concr. Res., 1997, 27, 185-191.

26 Z. Pang, J. Chen, C. Dong and G. Yang, RSC Adv., 2014, 4, 29897-29900.

27 K. Tian, S. Qi, Y. Cheng, X. Chen and Z. Hu, J. Chromatogr. A, 2005, 1078, 181-187.

$28 \mathrm{H}$. Lateef, S. M. Grimes, P. Kewcharoenwong and B. J. Feinberg, J. Chem. Technol. Biotechnol., 2009, 84, 18181827.

29 Y. Fukaya, A. Sugimoto and H. Ohno, Biomacromolecules, 2006, 7, 3295-3297.

30 R. R. Krug, W. G. Hunter and R. A. Grieger, J. Phys. Chem., 1976, 80, 2335-2341.

31 R. R. Krug, W. G. Hunter and R. A. Grieger, J. Phys. Chem., 1976, 80, 2341-2351.

32 E. I. Alevizou and E. C. Voutsas, J. Phys. Chem., 2013, 62, 6978.

33 D. D. Laskar, J. Zeng, L. Yan, S. Chen and B. Yang, Ind. Crops Prod., 2013, 50, 391-399.

34 A. Tejado, C. Pena, J. Labidi, J. M. Echeverria and I. Mondragon, Bioresour. Technol., 2007, 98, 1655-1663.

35 R. K. Sharma, J. B. Wooten, V. L. Baliga, X. Lin, W. G. Chan and M. R. Hajaligol, Fuel, 2004, 83, 1469-1482.

36 Z. Zhang, J. Chen, Z. Pang, L. A. Lucia, F. Li and G. Yang, Bioresources, 2015, 10, 6565-6575.

37 J. Ko, Y. Shimizu, K. Ikeda, S. Kim, C. Park and S. Matsui, Bioresour. Technol., 2009, 100, 1622-1627.

38 K.-E. L. Eriksson, R. Blanchette and P. Ander, Microbial and enzymatic degradation of wood and wood components, Springer Science \& Business Media, 2012.

39 B. B. Hallac, P. Sannigrahi, Y. Pu, M. J. Ray, R. J. Murphy and A. J. Ragauskas, J. Agric. Food Chem., 2009, 57, 1275-1281.

40 R. E. Hage, N. Brosse, L. Chrusciel, C. Sanchez, P. Sannigrahi and A. J. Ragauskas, Polym. Degrad. Stab., 2009, 94, 16321638.

41 A. Granata and D. S. Argyropoulos, J. Agric. Food Chem., 1995, 43, 1538-1544.

42 T. Malutan, R. Nicu and V. I. Popa, Bioresources, 2007, 3, 1320.

43 R. Samuel, Y. Pu, B. Raman and A. J. Ragauskas, Appl. Biochem. Biotechnol., 2009, 162, 62-74.

44 V. Fierro, V. Tornefernandez and A. Celzard, Microporous Mesoporous Mater., 2006, 92, 243-250.

45 S. Kubo and J. F. Kadla, Biomacromolecules, 2005, 6, 28152821.

46 T. Rashid, C. F. Kait, I. Regupathi and T. Murugesan, Ind. Crops Prod., 2016, 84, 284-293.

47 C. Heitner, R. P. Beatson and D. Atack, J. Wood Chem. Technol., 2007, 2, 169-185. 